Pesq. Vet. Bras. 36(4):345-350, abril 2016 DOI: $10.1590 / \mathrm{S} 0100-736 \mathrm{X} 2016000400015$

\title{
Imunofenotipagem dos linfócitos positivos para indoleamina 2,3 dioxigenase (IDO) em cultura de células de placenta bovina ${ }^{1}$
}

\author{
Juliana Catoia ${ }^{2}$, Pedro K.F.C. Bianchi², Carlos E.M. Bruno ${ }^{2}$, Caio H.O. Carniatto², \\ Rafael M. Leandro², Aline N. Poscai², Ana R. de Lima3 ${ }^{3}$ e José R. Kfoury Junior²
}

\begin{abstract}
Catoia J., Bianchi P.K.F.C., Bruno C.E.M., Carniatto C.H.O., Leandro R.M., Poscai A.N., Lima A.R. \& Kfoury Junior J.R. 2016. [Phenotyping of the indoleamine 2,3 dioxygenase (IDO) positive lymphocytes in bovine placental cell culture.] Imunofenotipagem dos linfócitos positivos para indoleamina 2,3 dioxigenase (IDO) em cultura de células de placenta bovina. Pesquisa Veterinária Brasileira 36(4):345-350. Departamento de Cirurgia, Setor de Anatomia, Faculdade de Medicina Veterinária e Zootecnia, Universidade de São Paulo, Av. Prof. Dr. Orlando Marques de Paiva 87, São Paulo, SP 05508 270, Brazil. E-mail: jrobertok@usp.br

Pregnancy is a physiological state that requires immune adaptation in order to be successfully carried on. During this period, mother and fetus establish an immune tolerance status at the maternal fetal interface. Indoleamine 2,3-dioxygenase (IDO) plays an important role in maternal-fetal tolerance by metabolizing tryptophan, impairs by several pathways, mainly T CD8 cells proliferation. Several cell types are present in the maternal fetal interface and several of them can express IDO. Leucocytes with Th1 produce a cytokine known as interferon $\gamma$ that stimulates the expression of IDO in several cell types. Lymphocytes are divided into sub-populations according to their function and phenotype: T lymphocytes, B lymphocytes and natural killer cells (NK). Hormones also involved in this process where progesterone exerts decisive role on maternal immune response that may change gestational outcome and estrogen is essential for fetal maternal tolerance and maintenance of pregnancy. Therefore, the main objective of this study was to identify lymphocytes in the bovine placental cell culture that are sensitive to progesterone, estrogen and interferon $\gamma$, IDO expression in various gestational stages using flow cytometry. According to the results in the gestational period from 67.5 to 77.5 days with the addition of interferon $\gamma$ expression ID0 was slightly increased in TCD3 lymphocytes, CD4, and differently from the other T cells CD8 displayed an higher expression of the enzyme (4.48 \pm 2.12 to $8.65 \pm 4.91)$. In the period from 92.5 to 172.5 days the CD4 lymphocytes, CD8 and TCD25 showed a significant decrease of IDO expression $(\mathrm{p}<0.05)$. At the final stages between 195 and 222, 5 days TCD3 lymphocytes, CD4 and BCD25 increased expression when subjected to interferon $\gamma$ supplementation; however, CD8 T cells and NK cells showed no significant changes. Based on the results presented we can conclude that all cell types were able to express IDO by supplementation with interferon $\gamma$, and that T CD8 lymphocyte showed an highly significant increase of IDO expression, whereas estrogen increased the expression of IDO only in B lymphocytes (CD25), and progesterone decreased enzyme expression in T lymphocytes (CD3 and CD4) and in NK cells. These results suggest a regulatory mechanism of the immunological system by steroidal hormones during gestation, particularly by modulating IDO expression.
\end{abstract}

INDEX TERMS: Placenta, cattle, maternal-fetal tolerance, indoleamine 2,3 dioxygenase, lymphocytes.

\footnotetext{
${ }^{1}$ Recebido em 3 de fevereiro de 2015.

Aceito para publicação em 6 de fevereiro de 2016.

${ }^{2}$ Departamento de Cirurgia, Faculdade de Medicina Veterinária e Zootecnia, Universidade de São Paulo (USP), Av. Prof. Dr. Orlando Marques de Paiva 87, Cidade Universitária, São Paulo, SP 05508-270, Brasil. *Autor para correspondência: jrobertok@usp.br

${ }^{3}$ Instituto de Saúde e Produção Animal, Faculdade de Medicina Veterinária, Universidade Federal Rural da Amazônia (UFRA), Av. Presidente Tancredo Neves 2501, Bairro Montese, Belém, PA 66077-530, Brasil.
}

RESUMO.- A gestação é um estado fisiológico que exige adaptações imunológicas para que transcorra normalmente. Nesse período a mãe e o feto apresentam uma relação imunológica, ou seja, a interface materno fetal. A enzima indoleamina 2,3 dioxigenase (IDO) desempenha um papel importante na tolerância materno fetal, por ser responsável pela metabolização do triptofano, impedindo por diversas vias a proliferação principalmente de lin- 
fócitos TCD8. Diversos tipos celulares estão presentes na interface materno fetal e vários deles podem expressar a ID0. Os leucócitos com perfil Th1 produzem uma citocina conhecida: o interferon $\gamma$ que estimula a expressão da IDO em vários tipos celulares. Os linfócitos são divididos em subpopulações de acordo com sua função e fenótipo. Seus tipos incluem linfócitos T, linfócitos B e as células natural killer (NK). Hormônios também atuam nesse processo a progesterona que exerce função determinante sobre a resposta imunológica materna podendo alterar o prognóstico gestacional e o estrógeno essencial para a tolerância materno fetal e manutenção da prenhez. Dessa maneira este trabalho tem por objetivo principal identificar os linfócitos presentes na placenta bovina em cultivo que expressam IDO (linfócitos T, linfócitos B e células NK), frente a estimulação por progesterona, estrógeno e interferon $\gamma$ nas diversas fases gestacionais utilizando a citometria de fluxo. Segundo os resultados no período de 67,5 a 77, 5 dias com a adição de interferon $\gamma$ a expressão da enzima IDO aumentou discretamente nos linfócitos TCD3, TCD4, e diferente dos linfócitos T CD8 apresentaram uma elevada expressão da enzima $(4,48 \pm 2,12-$ $8,65 \pm 4,91)$. No período de 92,5 a 172, 5 dias os linfócitos TCD4, TCD8 e TCD25 apresentaram uma diminuição da IDO. No período final de 195 a 222,5 dias, os linfócitos TCD3, TCD4 e os BCD25 aumentaram a expressão da ID0 quando submetidos ao interferon $\gamma$, no entanto, os linfócitos T CD8 e as células NK não apresentaram alterações significativas. Com base nos resultados apresentados pode-se concluir que todos os tipos celulares foram capazes de expressar a IDO mediante a suplementação com interferon $\gamma$, sendo que o linfócito T CD8 apresentou uma diferença bastante significativa quanto ao aumento da IDO, já o estrógeno elevou a expressão da IDO somente nos linfócitos B (CD25) e a progesterona diminuiu a expressão da enzima nos linfócitos T (CD3 e CD4) e nas células NK. Estes resultados sugerem um mecanismo de regulação do sistema imunológico desempenhado pelos hormônios esteroides presentes durante o processo gestacional, particularmente pela modulação da expressão da IDO.

TERMOS DE INDEXAÇÃO: Placenta, bovinos, tolerância materno-fetal, indoleamina 2,3 dioxigenase, linfócitos.

\section{INTRODUÇÃO}

Dentre as principais atividades do agronegócio brasileiro a bovinocultura se destaca no cenário mundial. Desde o ano de 2004, o Brasil assumiu a liderança nas exportações com um quinto da carne comercializada internacionalmente e vendas para mais de 180 países (Mapa 2014).

Para manter o excelente nível de produção desses animais, os cuidados com seus aspectos reprodutivos são de extrema importância incluindo o melhor entendimento do desenvolvimento intrauterino do embrião e a relação existente junto à interface materno fetal (Marques et al. 2007).

A placenta é uma estrutura de grande importância para o desenvolvimento adequado do concepto, um órgão efêmero materno fetal que permite a transferência restrita de metabólitos e drogas por meio de áreas de permutas es- pecializadas. Além da implantação do embrião, estabelece a interface para nutrição e trocas gasosas entre a circulação materna e fetal, inicia o reconhecimento materno da gestação, alterando o envolvimento imunológico local e as funções cardiovasculares e metabólicas maternas pela produção de hormônios (Brolio et al. 2010, Alecsandru et al. 2015).

Diversas populações celulares estão presentes no tecido placentário e uterino, dentre elas os leucócitos, células especializadas na defesa do organismo e, que no útero gestante tem o papel da expressão de receptores que medeiam o reconhecimento do concepto principalmente no momento da invasão trofoblástica e, a produção de citocinas que regulam e modulam a resposta imune materna (Hunt 1994, Moffet-King 2002, Janeway et al. 2008, Rango 2008, Tizard 2009).

No momento da implantação placentária, é esperada uma reação imunológica contra o concepto, que carrega moléculas paternas que não são "próprias" ao organismo materno. No entanto, o embrião é reconhecido pelo sistema imune materno, sem que seja disparada uma resposta imunológica contra sua permanência e desenvolvimento naquele ambiente. Assim, o sistema imune materno garante um ambiente favorável para o desenvolvimento embrionário e fetal. Esse fenômeno pode ser designado "Tolerância Imunológica" (Michelon et al. 2006, Wira et al. 2015).

Dentre os diversos mecanismos da tolerância materno fetal destaca-se a indoleamina 2,3 dioxigenase (IDO), enzima presente em alguns tecidos nos mamíferos, que cataboliza o triptofano, levando as células $\mathrm{T}$ efetoras à apoptose (Mbongue et al. 2015), seja devido ao estado de carência deste componente no microambiente placentário, seja pelos catabólitos tóxicos produzidos durante seu catabolismo, principalmente a quinurenina (Liang 2006, Ban et al. 2013).

A gestação é um estado fisiológico que exige adaptações imunológicas para que transcorra normalmente (Feliciano et al. 2012). Esse período é caracterizado por altas concentrações de progesterona, hormônio essencial para a manutenção da gestação, por promover o desenvolvimento endometrial, manter a integridade placentária, reduzir a atividade miometrial e a sensibilidade a ocitocina (Concannon 1986, Papamitsou et al. 2011). Com o decorrer da gestação, a produção de estrógeno ocorre em vários tecidos, contribuindo para o crescimento uterino necessário para o desenvolvimento embrionário e fetal bem-sucedido (Dobson et al. 1993, Wood 1999, Kindahl 2002, Wira et al. 2015).

A capacidade de expressão da IDO ocorre em diversas células presentes na placenta, inclusive por alguns leucócitos, esta expressão pode ser influenciada pelo estradiol e pela progesterona. Ainda é desconhecida quais destas células efetivamente são influenciadas por esses hormônios e quais efeitos causam. Devida a falta desse conhecimento e pela importância que essas células desempenham, o trabalho teve como objetivo a identificação dos linfócitos presentes no útero gravídico de vacas que expressam IDO (linfócitos T, linfócitos B e células NK), perante a estimulação por progesterona, estrógeno e interferon $\gamma$. 


\section{MATERIAL E MÉTODOS}

Foi utilizado um total de 15 amostras, de placentas de gestações de fetos normais coletados em abatedouro localizado em São José dos Campos (Frigorífico- Frigo Fênix Comércio Distribuidora de Carnes Ltda.), sendo cinco animais representativos de cada um dos três terços gestacionais principais, sendo: terço 1- (67,5 a 77,5 dias), terço 2- (92,5 a 172,5 dias) e terço 3- (195 a 222,5 dias).

0 projeto foi desenvolvido na Faculdade de Medicina Veterinária e Zootecnia da Universidade de São Paulo, FMVZ-USP mediante a aprovação da Comissão de Bioética da mesma Universidade (protocolo ${ }^{\circ} 2943 / 2013$ ).

Os placentônios coletados foram lavados em tampão fosfato (PBS), armazenados em sacos plásticos (Pratsy Zip 18x23cm) e mantidos sob refrigeração até o processamento. Com o auxilio de pinça e tesoura estéreis o material coletado foi colocado sobre uma placa de Petri para a retirada do excesso alantoidiano. Os placentônios foram seccionados e fragmentados da região da interface materno fetal, entre a carúncula uterina e o cotilédone fetal. Seguindo a aplicação da técnica de separação mecânica os fragmentos foram coletados sobre uma malha de aço 150 mesh de diâmetro e com auxílio de uma seringa de $10 \mathrm{ml}$ e meio de cultura D-MEM (Sigma Aldrich, USA) com 10\% de soro fetal bovino e antibiótico, os fragmentos foram pressionados contra a malha para a separação celular. Tizard 2009,

As células separadas foram colocadas em tubos de $50 \mathrm{ml}$ e submetidas à centrifugação (1800xg, por 5 min a $20^{\circ} \mathrm{C}$ ) e após a centrifugação o meio foi removido e as células foram suspensas em $30 \mathrm{ml}$ de meio de cultura. Após esse processo realizou-se a contagem de células e a estimativa da viabilidade das células através do método de exclusão por azul de tripan, onde as células foram postas em placas de 48 poços em uma concentração de $1 \times 10^{6}$ células $/ 250 \mu \mathrm{l}$, sendo incubadas à $37^{\circ} \mathrm{C}$ e $5 \%$ de $\mathrm{CO} 2$ até o início das análises.

No início do tratamento os fatores foram adicionados e os tratamentos assim estabelecidos:

a) Grupo ST = Sem tratamento, somente meio de cultura (D-MEM-Sigma Aldrich, USA), $200 \mu$;

b) Grupo P = D-MEM + Progesterona (acetato de medroxiprogesterona Promone-E) (Pfizer- Brasil) ${ }^{\circledR}, 1 \mu \mathrm{l} / 200 \mu \mathrm{l}$;

c) Grupo E = D-MEM + Estrógeno (ECP = cipionato de estradiol) (Pfizer-Brasil) ${ }^{\circledR}, 2,5 \mu \mathrm{l} / 200 \mu \mathrm{l}$;

d) Grupo I = D-MEM + Interferon $\gamma$ (Millipore, USA), $1 \mu \mathrm{l} / 200 \mu \mathrm{l}$.

Com o auxilio do citômetro de fluxo, foi realizada a imunofenotipagem das células conjunta com a verificação da expressão da IDO foi realizada com a utilização da citometria de fluxo. As células em cultura foram soltas das placas e a suspensão celular foi lavada em dois ciclos de $1800 \mathrm{~g}$, durante $5 \mathrm{~min}$ a $20^{\circ} \mathrm{C}$. Em seguida, o sobrenadante foi retirado, as células ressuspendidas em PBS (0,1 M) e permeabilizadas com triton-X (Inlab-Brasil) 0,1\% por 20 minutos e, então as células foram novamente lavadas e ressuspendidas em PBS $(0,1 \mathrm{M})$. Posteriormente foram incubados individualmente as células em cultura, os anticorpos primários: anti-CD3 bovino (VMRD USA), anti-CD4 bovino (VMRD USA), anti-
-CD8 bovino (VMRD USA), anti-CD25 (VMRD USA) e anti-CD335 (VMRD USA), recebendo também a adição do anticorpo primário Anti-IDO (indoleamina 2,3 dioxygenase (EB 09548 - Goat Anti-Indol1- Everest Biotech, USA). Após 30 minutos foram realizadas mais duas lavagens em PBS a $1800 \mathrm{x}$ g, durante 5 minutos a $20^{\circ} \mathrm{C}$, em seguida as amostras foram incubadas com os respectivos anticorpos secundários Donkey anti goat PE (LSBio-USA ) e o Rabbit anti mouse FITC (LSBio, USA) e por mais 30 min na geladeira. Após esse procedimento as células foram lavadas em PBS as duas últimas vezes $\left(1800 \mathrm{x}\right.$ g, durante 5 minutos a $20^{\circ} \mathrm{C}$ ) e por fim, ressuspendidas em Tampão FACS para serem analisadas em citometria de fluxo (BD FACS Calibur). Controles para autofluorescência e marcação cruzada pelo anticorpo secundário foram realizados com grupos contendo somente células e grupos contendo células e o anticorpo secundário, respectivamente.

\section{RESULTADOS}

As células bovinas das várias fases gestacionais foram analisadas no período de 24 horas, perante os tipos celulares linfócitos T, linfócitos B e células NK após a adição de fatores: progesterona, estrógeno e interferon $\gamma$, verificando os níveis de expressão da enzima IDO nas respectivas células.

No inicio da gestação $(67,5$ a 77,5 dias), todos os tipos celulares analisados (linfócitos T, B e Células NK), quando submetidos à suplementação com estrógeno, apresentaram uma diminuição na expressão de IDO. Já, após a adição do interferon $\gamma$ a expressão da enzima foi levemente elevada nos linfócitos TCD3, TCD4, no entanto, o linfócito TCD8, diferente das demais células, apresentou uma diferença bastante significativa, caracterizando uma elevada expressão da enzima $(4,48 \pm 2,12-8,65 \pm 4,91)$ no primeiro terço gestacional (Quadro 1).

Os animais com idade gestacional de 92,5 a 172,5 dias mostraram que apenas os linfócitos TCD8, quando suplementados com progesterona, elevaram a expressão de IDO $(1,68 \pm 0,82$ a $2,5 \pm 1,34)$, enquanto as outras células TCD3, TCD4, BCD25 e NK apresentaram uma diminuição na expressão da enzima, sendo um valor significativo apenas para as células TCD4 que apresentaram uma diminuição na expressão da enzima. A suplementação com estrógeno, nesse período, exibiu um aumento da IDO somente nos linfócitos TCD3 e nas células NK. Os linfócitos TCD4, TCD8 e linfócitos B (CD25) apresentaram uma diminuição da IDO, em que, todos, tiveram um valor de p menor que 0,05 , caracterizando a existência de uma diferença significativa entre o grupo controle e os linfócitos (Quadro 2)

Para os animais concentrados no período de 195 a 222,5 dias de gestação, as células NK e os linfócitos TCD8 elevaram a expressão da enzima perante a suplementação com progesterona, porém, as demais células apresentaram uma diminuição da enzima quando submetidas à suplementação com a mesma (progesterona).

Quadro 1. Valores médio e o respectivo desvio padrão da expressão da IDO dos animais no período de 67,5 a 77, 5 dias

\begin{tabular}{lccccc}
\hline Tipo celular & $\begin{array}{c}\text { Linfócitos T } \\
\text { (CD3) }\end{array}$ & $\begin{array}{c}\text { Linfócitos T } \\
\text { (CD4) }\end{array}$ & $\begin{array}{c}\text { Linfócitos T } \\
\text { (CD8) }\end{array}$ & $\begin{array}{c}\text { Linfócitos B } \\
\text { (CD25) }\end{array}$ & $\begin{array}{c}\text { Células NK } \\
\text { (CD335) }\end{array}$ \\
\hline Controle & $4,83 \pm 3,56$ & $5,67 \pm 2,50$ & $4,48 \pm 2,12$ & $3,15 \pm 2,72$ & $3,65 \pm 2,79$ \\
Progesterona & $3,67 \pm 2,75$ & $3,57 \pm 1,41$ & $4,80 \pm 2,94$ & $4,28 \pm 2,27$ & $3,52 \pm 2,27$ \\
Estrógeno & $2,33 \pm 1,35$ & $2,67 \pm 1,79$ & $3,12 \pm 1,69$ & $2,15 \pm 0,56$ & $2,34 \pm 0,66$ \\
Interferon & $5,37 \pm 2,63$ & $5,95 \pm 2,01 p=0,03 *$ & $8,65 \pm 4,91 \mathrm{p}=0,04 *$ & $6,0 \pm 2,97$ & $8,9 \pm 7,03$
\end{tabular}


Quadro 2. Valores médio e o respectivo desvio padrão da expressão da IDO dos animais no período de 92,5 a 172,5 dias

\begin{tabular}{|c|c|c|c|c|c|}
\hline Tipo celular & $\begin{array}{l}\text { Linfócitos T } \\
\text { (CD3) }\end{array}$ & $\begin{array}{l}\text { Linfócitos T } \\
\text { (CD4) }\end{array}$ & $\begin{array}{l}\text { Linfócitos T } \\
\text { (CD8) }\end{array}$ & $\begin{array}{l}\text { Linfócitos B } \\
\text { (CD25) }\end{array}$ & $\begin{array}{c}\text { Células NK } \\
\text { (CD335) }\end{array}$ \\
\hline Controle & $1,9 \pm 0,7$ & $2,51 \pm 0,69$ & $1,68 \pm 0,82$ & $1,67 \pm 0,82$ & $\begin{array}{c}1,31 \pm 0,22 \\
p=0,04^{*}\end{array}$ \\
\hline Progesterona & $1,43 \pm 0,34$ & $\begin{array}{c}0,99 \pm 0,21 \\
\mathrm{p}=0,02^{*}\end{array}$ & $2,5 \pm 1,34$ & $1,44 \pm 0,63$ & $2,9 \pm 2,35$ \\
\hline Estrógeno & $2,81 \pm 4,52$ & $\begin{array}{c}0,89 \pm 0,6 \\
p=0,023^{*}\end{array}$ & $\begin{array}{c}0,87 \pm 0,44 \\
\mathrm{p}=0,02^{*}\end{array}$ & $\begin{array}{c}1,10 \pm 0,32 \\
\mathrm{p}=0,03^{*}\end{array}$ & $1,34 \pm 0,57$ \\
\hline Interferon & $\begin{array}{l}0,62 \pm 0,84 \\
p=0,018^{*}\end{array}$ & $1,28 \pm 0,54$ & $\begin{array}{c}1,20 \pm 0,61 \\
\mathrm{p}=0,04^{*}\end{array}$ & $1,31 \pm 0,71$ & $1,17 \pm 0,86$ \\
\hline
\end{tabular}

Quadro 3. Valores médio e o respectivo desvio padrão da expressão da IDO dos animais no período de 195 a 222,5 dias

\begin{tabular}{lccccc}
\hline Tipo celular & $\begin{array}{c}\text { Linfócitos T } \\
\text { (CD3) }\end{array}$ & $\begin{array}{c}\text { Linfócitos T } \\
\text { (CD4) }\end{array}$ & $\begin{array}{c}\text { Linfócitos T } \\
\text { (CD8) }\end{array}$ & $\begin{array}{c}\text { Linfócitos B } \\
\text { (CD25) }\end{array}$ & $\begin{array}{c}\text { Células NK } \\
\text { (CD335) }\end{array}$ \\
\hline Controle & $2,97 \pm 1,59$ & $2,40 \pm 1,50$ & $3,91 \pm 2,76$ & $2,72 \pm 1,85$ & $3,96 \pm 3,17$ \\
Progesterona & $3,71 \pm 2,02$ & $3,55 \pm 1,74$ & $3,67 \pm 2,76$ & $3,47 \pm 1,82$ & $2,63 \pm 1,65$ \\
Estrógeno & $2,93 \pm 2,14$ & $3,52 \pm 2,23$ & $2,56 \pm 1,87$ & $5,32 \pm 2,32$ & $4,24 \pm 3,44$ \\
Interferon & $2,77 \pm 2,44$ & $2,98 \pm 1,96$ & $3,23 \pm 2,40$ & $3,44 \pm 2,98$ & $3,00 \pm 1,31$
\end{tabular}

Neste período (195 a 222,5 dias), com a adição do estrógeno á cultura, houve um aumento na expressão de IDO em todas as células, exceto nos linfócitos TCD8 (Quadro 3).

Os Linfócitos TCD3, TCD4 e os linfócitos B (CD25) aumentaram a expressão da IDO quando submetidos ao interferon $\gamma$, no entanto, os linfócitos TCD8 e as células NK não apresentaram alterações significativas na expressão da enzima após a suplementação com a citocina (interferon $\gamma$ ) (Quadro 3).

\section{DISCUSSÃO}

O trabalho demostrou que a expressão de IDO é influenciada pelos fatores adicionados experimentalmente às culturas. Verificou-se que tais hormônios (progesterona e estrógeno) e o interferon $\gamma$, alteram a expressão de IDO nas diferentes idades gestacionais, sugerindo a participação destes compostos em mecanismos de imunossupressão, ainda não totalmente esclarecido, nas células da região uteroplacentária.

0 interferon $\gamma$, uma citocina produzida por leucócitos com perfil Th1, grupo celular responsável por favorecerem uma resposta pró-inflamatória, conhecida por estimular a expressão de IDO em vários tipos celulares, incluindo os leucócitos, em que se liga especificamente à região do gene que promove a transcrição da proteína (Yoshida et al. 1981, Yasui et al. 1986, Liang et al. 2006).

0 efeito mais interessante relacionado ao interferon $\gamma$ foi a elevação da expressão de ID0 nos linfócitos TCD8 no período inicial da gestação $(67,5$ a 77,5 dias). Sabe-se que os linfócitos TCD8 são altamente agressivos em sua resposta a um agente não próprio (Tizard 2009), que é o caso do embrião ao se implantar na parede uterina, pois o mesmo possui moléculas de MHC paternas que são, potencialmente, reconhecidas pelo organismo materno como um agente não próprio, podendo desencadear uma reposta imunológica materna contra o embrião, em que os linfócitos TCD8 podem causar sérias lesões ao alo enxerto.

A presença da IDO neste tipo celular, logo nos estágios iniciais da gestação, no período em que o embrião entra em contato com o sistema imunológico materno torna-se muito interessante para a sobrevivência do concepto, pois a IDO pode levar os linfócitos T CD8 à apoptose, bem como as células imunológicas que estão ao seu redor, sugerindo um controle da resposta imunológica desencadeado pela citocina pró-inflamatória, o interferon y.

Nas células provenientes da gestação com idade avançada (195 a 222,5 dias) o interferon $\gamma$ elevou a expressão de IDO nos linfócitos TCD3, TCD4 e linfócitos B, não causando alterações significativas nos linfócitos TCD8. Nesse período gestacional o concepto já está bastante desenvolvido e, já entrou em contato com o sistema imunológico materno, em que a resposta imunológica materna aguda contra o alo enxerto pode ser branda devido à diminuição dos linfócitos TCD8 nos períodos anteriores a este, causada pela expressão da IDO neste grupo celular. Além disso, a espécie bovina apresenta uma placenta sinepiteliocorial cotiledonária, onde se encontra pontos de adesão entre o cório-alantoide e o endométrio, sendo assim, ocorre um pequeno grau de invasão de células de fetais no tecido materno propondo a necessidade de tolerância imunológica materna para que não aconteça a rejeição fetal. 0 aumento da IDO nos linfócitos TCD3 e TCD4 pode ser causado indiretamente pelas células apresentadoras de antígenos, pois sabe-se que estão presentes nessa região durante todo processo gestacional (Valente et al. 1992, Tenbrock \& Tembrock 2011). Quando estimuladas pelo interferon $\gamma$, principalmente as células dendríticas irão estimular os linfócitos TCD4 pela ligação das moléculas de B7, presentes nas DCs, com as moléculas de CTLA4, presente nos LTCD4 (Palafox et al. 2010, Harden, Egilmez. 2012). Dessa maneira, com a presença da IDO nos linfócitos TCD4, as células ao redor entrariam em apoptose devido à falta de triptofano e aos catabólitos tóxicos gerados pela sua quebra, atenuando a reposta imunológica na região da interface materno fetal. 0 estrógeno, hormônio em altas concentrações durante a gestação (Østensen 1999), possui efeitos específicos sobre as células T e B, participando da 
proliferação e da diferenciação destas células (Leaños-Miranda et al. 2001). Nos animais com gestação mais adiantada a concentração estrogênica é bastante elevada, por isso, o seu efeito nas células imunológicas, estudadas, é mais elevado nos animais com idade gestacional avançada. Após a adição do estrógeno às culturas de células de animais com idade gestacional entre 195 a 222,5 dias a expressão de IDO foi alterada, em que o estrógeno elevou a expressão da enzima em todos os tipos celulares analisados, exceto no linfócito TCD8, que pode ter entrado em apoptose devido à ação da IDO nas outras células, privando, como consequência, o linfócito TCD8 do triptofano, fazendo com que os mesmos não apresentassem alteração perante a expressão da enzima. Conforme observado, o estrógeno no início da gestação diminui a expressão da enzima em todos os tipos celulares. Este fato torna-se bastante relevante quando comparado à ação do estrógeno nas células imunológicas, que é responsável por causar alterações na produção de citocinas (Barrera et al. 2007), podendo desencadear respostas imunológicas diferenciadas, de acordo com a necessidade do momento.

Levando em conta o inicio da gestação e a alta resposta inflamatória devido à implantação embrionária, este hormônio pode agir como um regulador na expressão desta enzima, pois apesar da diminuição da sua expressão, a mesma não para de ser produzida totalmente, podendo ser estimulada por algumas citocinas anti-inflamatórias produzidas por células imunológicas estimuladas pelo estrógeno, no entanto, tais citocinas, não causam uma alta expressão da enzima se comparadas a ação de citocinas pro-inflamatórias, como o interferon $\gamma$. Durante a gestação, especificamente nos períodos finais, o estrógeno está em altas concentrações no organismo materno. Um fato importante, considerando as células precursoras da resposta imunológica primária é que a alta concentração de estrógeno faz com que as células dendríticas imaturas tornem-se maduras com grande rapidez, principalmente pelo estímulo aos receptores CD86, presente nas DCs (Spaggiari et al. 2009). Com uma alta concentração de células dendríticas, na região uteroplacentária, poderia haver o desenvolvimento de uma resposta imunológica bastante severa contra o alo enxerto, no entanto, apesar de o estrógeno estimular o amadurecimento das DCs, o mesmo age para contrabalancear esta reação inflamatória que as DCs poderiam causar, estimulando, também, a expressão de IDO nas DCs, controlando o mecanismo inflamatório nessa região. Nas células NK de animais com 92 a 172 dias de gestação, sofreram uma elevação na expressão de IDO quando submetidas ao tratamento com o estrógeno. Sabe-se que na presença deste hormônio, as células NK têm a sua ação diminuída, ou seja, elas perdem a capacidade de cito toxicidade (Mellor \& Munn. 2001). Sugere-se que haja a existência de uma relação entre a presença de IDO e a perda da função das células NK, ou seja, pode ser que a expressão de IDO seja estimulada pelo estrógeno nessas células, com isso, a enzima quebra o triptofano, impedindo a proliferação e a ação das células NK, bem como das células que estão presente neste microambiente. A progesterona, hormônio de atuação na manutenção da gestação em humanos e animais (Steckel et al. 2003), também é capaz de induzir a expressão da IDO nas células presentes no ambiente uterino-placentá- rio (Barrera et al. 2007). Uma das suas funções é a proteção do concepto contra o ataque do sistema imune materno por inibição de células T (Siiteri et al. 1977, Steckel et al. 2003, Peltier 2003, Ligam et al. 2005), também inibe diretamente a estimulação da resposta imuno-endócrina através da sua interação com receptores de membrana (Peltier 2003). Foi observado que a ação da progesterona não causa elevações significativas sob a expressão de IDO nas células das diferentes idades gestacionais analisadas. Porém, um fato bastante relevante é a manutenção da expressão da IDO em todas as células analisadas, ou seja, a progesterona pode não elevar a expressão de ID0, mas pode ser responsável por manter sempre em níveis controlados, necessários para a manutenção da gestação. A ação da progesterona nas células imunológicas é bastante conhecida, como nas células dendríticas, em que estimula o amadurecimento das DCs imaturas (Liang et al. 2006). Tais células não são capazes de estimular os linfócitos T diretamente, no entanto terminam o seu amadurecimento em um linfonodo regional, fagocitando um antígeno, que pode ser proveniente do embrião, e apresentam, via MHC, para as células T, induzindo a diferenciação dos linfócitos Th0 em Th1 ou Th2, dependendo do estímulo, que no início da gestação, pode ser um estímulo pró-inflamatório, devido à implantação embrionária. Com isso, citocinas pró-inflamatórias serão produzidas, podendo estimular a expressão de IDO nas células presentes neste microambiente. Ainda, se o estímulo for anti-inflamatório, a progesterona estimula a produção da citocina TGF- $\beta$ que também é capaz de estimular a produção de IDO pela via não canônica (NFkB), perpetuando a expressão da enzima (Barrera et al. 2007). Contudo, a expressão da enzima foi verificada em todos os períodos gestacionais, em maior ou em menor quantidade. Os fatores adicionados às culturas podem alterar a expressão da enzima, nos mostrando que fazem parte de uma rede intrincada de mecanismos que controlam a reação imunológica na região da interface materno-fetal, colaborando com a tolerância ao feto semi-alogenêico. A presença da IDO em todos os períodos gestacionais mostra a sua importância nos mecanismos de tolerância, no entanto, sabe-se que existem inúmeros outros mecanismos que colaboram com a tolerância materno-fetal e que todos esses mecanismos devem agir em conjunto para levar uma gestação a termo. Por fim, para compreender como ocorre a modulação da expressão da IDO nas células imunológicas são necessários mais estudos relacionados à mecanismos de ativação e inibição deste enzima, em regiões que é altamente expressa, como na interface materno fetal e na maioria dos tumores. No caso dos bovinos, estes que são animais essenciais e extremamente úteis para o estudo dos efeitos modulatórios da IDO no que se refere às modificações celulares e funcionais no período gestacional, pois são animais de grande interesse e importância na pecuária do país com altos índices de produção de carne e leite, e também os problemas reprodutivos, como o aborto que podem estar relacionados à rejeição fetal.

Considerando as análises realizadas neste trabalho, pode-se concluir que a IDO foi enunciada em todos os tipos celulares, contudo só algumas células responderam de maneira positiva aos fatores empregados. Os linfócitos B 
(CD25) foram os mais sensíveis em relação a estrógeno, ou seja, foi o tipo celular que mais elevou a expressão da IDO. A progesterona foi o fator que diminuiu a expressão da IDO nos linfócitos T (CD3, CD4) e as células NK. Dentre os fatores utilizados o interferon y foi o que aumentou a expressão da IDO em todos os tipos celulares analisados, mesmo que em algumas células foi um aumento discreto.

\section{REFERÊNCIAS}

Alecsandru D. \& García-Velasco J.A. 2015. Immunology and human reproduction. Curr. Opin. Obstet. Gynecol. 27:231-234.

Ban Y., Chang Y., Dong B., Kong B. \& Qu X. 2013. Indoleamine 2,3-dioxygenase levels at the normal and recurrent spontaneous abortion fetal-maternal interface. J. Int. Med. Res. 41:1139-1145.

Barrera D., Avila E. \& Dias L. 2007. Papel inmunológico de la progesterone em el mantenimiento del embarazo. Revta Invest. Clin. 59:139-145.

Brolio M.P., Ambrósio C.E., Franciolli A.R., Morini A.C., Guerra R.R. \& Miglino M.A. 2010. A barreira placentária e sua função de transparência nutricional. Revta Bras. Reprod. Anim. 34:222-232.

Concannon P.W. 1986. Canine pregnancy and parturition. Vet. Clin. Norh Am., Small Anim. Pract. 16:453-475,.

Dobson H., Rowan T.G., Kippax I.S. \& Humblot P. 1993. Assessment of fetal, number, and fetal and placental viability throughout pregnancy in cattle. Theriogenology 40:411-425.

Feliciano M.A.R., Aquino A.A., Coutinho L.N. \& Vicente W.R.R. 2012. Imunologia na gestação de cadelas: revisão de literatura. Revta Bras. Reprod. Anim. 36:158-162.

Harden J.L. \& Egilmez N.K. 2012. Indoleamine 2, 3-dioxygenase and dendritic cell tolerogenicity. Immunol. Invest. 41:738-764.

Hunt J.S. 1994. Immunologically relevant cells in the uterus. Biol. Reprod. 50:461-466.

Janeway C., Murphy K., Travers P. \& Walport M. 2008. Jeneway's immunobiology: the immune system in health and disease. 7th ed. Abingdon, New York. 835p.

Kindahl H., Kornmatitsuk B., Königsson K. \& Gustafsson H. 2002. Endocrine changes in late bovine pregnancy with special emphasis on fetal well-being. Dom. Anim. Endocrinol. 23:321-328.

Leaños-Miranda A., Pascoe-Lira D., Chávez-Rueda K.A. \& Blanco-Favela F. 2001. Persistence of macroprolactinemia due to antiprolactin autoantibody before, during, and after pregnancy in a woman with systemic lupus erythematosus. J. Clin. Endocrinol. Metabolism 86:2619-2624.

Liang J., Sun L., Wang Q. \& Hou Y. 2006. Progesterone regulates mouse dendrictic cells differentiation and maturation. Int. Immunopharmacol. 6:830-838.

Ligam P., Manuelpillai U., Walace E.M. \& Walker D. 2005. Localisation of indoleamine 2,3 dioxygenase and kynurenine hydroxylase in the human placenta and decidua: implications for role of the kynurenine pathway in pregnancy. Placenta 26:498-504.

Marques R.S., Vulcano M., Cazerta S.M.M., Miglino M.A., Assis Neto A.C. \& Pereira F.T.V. 2007. Caracterização morfológica da região intercaruncular de vacas e búfalas gestantes. Biotemas 20:103-114.

Mbongue M.J., Nicholas A.D., Torrez T.W., Kim N.S., Firek F.A. \& Langridge H.R.W. 2015. The Role of Indoleamine 2, 3-Dioxygenase in Immune Suppression and Autoimmunity. Vaccines 3:703-729.
Mellor A.L. \& Munn D.H. 2001. Tryptophan catabolism prevents maternal $\mathrm{T}$ cells from activating lethal antifetal immune responses. J. Reprod. Immunol. 52:5-13.

Michelon T., Silveira J.G., Graudens M. \& Neumann J. 2006. Imunologia da gestação. Revta Assoc. Méd. RGS 50:145-151.

Ministério da Agricultura Pecuária e Abastecimento 2014. Exportação de Bovinos. Disponível em <http:// <www.agricultura.gov.br> Acesso em 23 out. 2014.

Moffet-King A. 2002. Natural killer and pregnancy. Nat. Revs Immunol. 2:656-663.

Østensen M. 1999. Sex hormones and pregnancy in rheumatoid arthritis and systemic lupus erythematosus. Annals NY Acad. Sci. 22:131-143.

Palafox D., Llorente L., Alberú J., Torres-Machorro A., Camorlinga N., Rodríguez C. \& Granados J. 2010. The role of indoleamina 2,3 dioxygenase in the induction of immune tolerance in organ transplantation. Transpl. Revs 24:160-165.

Papamitsou T., Chatzistmatiou M., Grammatikopoulou D., Papadopoulou K., Lakis S., Economou Z., Papasopoulou C. \& Sioga A. 2011. Low expression of progesterone receptor A in intermediate trophoblastos miscarriages. Histol Histopathol. 26:609-614.

Peltier M.R. 2003. Immunology of term and labor. Reprod. Biol. Endocrinol. 1:122.

Rango U.V. 2008. Effects of trophoblast invasion on the distribution of leukocytes in uterine and tubal implantation sites. Fertil. Steril. 76:116124.

Siiteri P.K., Febres F. \& Clemens L.E. 1977. Progesterone and maintenance of pregnancy: is progesterone nature's immunosuppressant? Annual NY Acad. Sci. 11:384-397.

Spaggiari G.M., Abdelrazik H., Becchetti F. \& Moretta L. 2009. MSCs inhibit monocyte-derived DC maturation and function by selectively interfering with the generation of immature DCs: central role of MSC-derived prostaglandin E2. Blood 113:6576-6583.

Steckel N.K., Kuhn U., Beelen D.W. \& Elmaagacli A.H. 2003. Indoleamine 2,3- dioxygenase expression in patients with acute graft-versus-host disease after allogeneic stem cell transplantation and in pregnant women: association with the induction of allogeneic immune tolerance? Scand. J. Immunol. 57:185-19.

Tizard I.R. 2009. Imunologia Veterinária. 8ª ed. Elsevier, Rio de Janeiro.

Tenbrock K.O. \& Tembrock K. 2011. Inflammatory cytokines in systemic Lupus Erythematosus. J. Biomed. Biotechnol. 20:11-14.

Valente G., Ozmen L., Novelli F., Geuna M., Palestro G., Forni G. \& Garotta G. 1992. Distribution of interferon-gamma receptor in human tissues. Eur. J. Immunol. 22:2403-2412.

Wira R.C., Garcia M.R. \& Patel M.V. 2015. The role of sex hormones in immune protection of the female reproductive tract. Nat. Rev. Immunol. 15:217-230

Wood C.E. 1999. Control of parturition in ruminants. J. Reprod. Fertil. 54(Suppl.):115-126.

Yasui H., Takai K., Yoshida R. \& Hayaishi O. 1986. O Interferon y enhances tryptophan metabolismo by inducing pulmonary indoleamine 2,3 dioxygenase: it's possible occurrence in cancer patients. Proc. Natl Acad. Sci. USA 83:622-626.

Yoshida R., Imanishi J., Oku T., Kishida T. \& Hayashi O. 1981. Induction of pulmonary indoleamine 2,3 dioxygenase by interferon y. Proc. Natl Acad. Sci. USA 78:129-132. 